\title{
PARTICLE CONCENTRATIONS IN A CHURCH DURING DIFFERENT WEATHER CONDITIONS - A CASE STUDY
}

\author{
Bernard Polednik ${ }^{1}$, Aleksandra Polednik ${ }^{2}$ \\ 1 Lublin University ofTechnology,Nadbystrzycka40B,20-618Lublin,Poland,e-mail:b.polednik@wis.pol.lublin.pl \\ 2 CMS Cameron McKenna, Warsaw, Poland
}

Received: 2016.08.16 Accepted: 2016.09.26 Published: 2016.11.01

\begin{abstract}
The purpose of this study is to report particle number (PN) and particle mass (PM) concentration changes in the church during three 60-minute Masses held on a cloudy, sunny and rainy day. At each Mass with a similar number of participants the same number of candles was lit and incense was burned. The highest average $\mathrm{PN}_{1}$ and $\mathrm{PM}_{1}$ concentrations of submicrometer particles which respectively amounted to $23.9 \mathrm{pt} / \mathrm{cm}^{3}$ and $241.1 \mu \mathrm{g} / \mathrm{m}^{3}$ were obtained for the Mass held on a rainy day. During that Mass the maximum $\mathrm{PN}_{1}$ and $\mathrm{PM}_{1}$ concentrations (amounting to $59.4 \cdot 10^{3} \mathrm{pt} / \mathrm{cm}^{3}$ and $632 \mu \mathrm{g} / \mathrm{m}^{3}$ ) were respectively about 15 and 39 times higher than the church background levels. The greatest number of submicrometer particles (about $18.5 \cdot 10^{9}$ ) was inhaled by an average participant of the Mass held on a sunny day and it was approximately 7 times higher than the number that would have been inhaled at the same time outdoors. The greatest mass of such particles (about $195.4 \mu \mathrm{g}$ ) was inhaled by an average participant of the Mass held on a rainy day and it was approximately 8 times higher than the mass of particles that would have been inhaled outdoors during the same time.
\end{abstract}

Keywords: church microclimate; incense burning; mass attendant; particle exposure; weather

\section{INTRODUCTION}

Numerous studies confirm that pollutant concentrations can be significantly higher in indoor environments than outdoors [1-4]. Most pollutants present in indoor environments, including aerosol particles, are considered harmful to room users. In the case of aerosol particles, detrimental health effects depend on their number and mass concentrations, size, chemical composition and exposure time..$^{5-7}$ Apart from being infiltrated from the outdoor environment, significant sources of such pollutants may also be found indoors. This particularly concerns premises in which relatively large numbers of users stay over fairly long periods of time. Such premises include churches and other places of worship in which aerosol particles are generated during religious ceremonies. The physical activity of the ceremony participants and the related resuspension pro- cesses are generally responsible for the increase of indoor coarse particle concentrations [8,9]. In turn, indoor combustion processes such as burning candles or incense are the main source of fine and ultrafine particles $[10,11]$. All the generated particles may have detrimental health effects and may also contribute to the deterioration of the works of art inside churches [12-14]. Nevertheless, information gathered so far on this subject is scarce. The performed studies concerned only a small number of selected churches of few architectural styles. Moreover, such studies were conducted mostly during important holidays or simulated Masses while the changes of indoor and outdoor conditions and the resulting implications were rather not considered. Weber15 carried out measurements of particle concentration changes in a Gothic Roman Catholic church in Germany during Christmas and New Year's Eve church services with particular focus on the churchgo- 
ers' exposure to particles due to the length of the services and the number of Mass participants. It was found that burning the incense caused significant increases of indoor particle concentrations while candle burning was considered negligible in this case. The research conducted by Loupa et al. [12] in Byzantine Orthodox churches in Cyprus revealed that the presence and activity of the churchgoers as well as the presence of visitors between Masses had a significant impact on the indoor particle concentration levels. Burning the incense and candles resulted in a considerable particle concentration increase. The impact of radiant heating on the transportation and deposition of suspended particulate matter in two churches in Poland which differed in terms of their architectural style (late Baroque/Rococo and Gothic) and construction materials (wood and brick) was examined by Samek et al. [16]. The heating system was fund not to increase the particle concentrations in those churches and specifically no resuspension processes were observed. Recently Mleczkowska et al. [17] have published a research concerning particle penetration and deposition inside two Catholic churches in southern Poland - a Gothic church made of brick and a small wooden church. The research provided evidence that deposition velocities for the considered fine and coarse particles were consistent in both monitored churches despite the differences in their architectural style, size and construction materials.

The evaluation of health risks resulting from regular exposure to candles or incense-derived particulate matter was performed by de Kok et al. [18] on the basis of measurements performed in a Romanesque Roman Catholic church in the Netherlands. The measurement results suggested that such exposure may increase the risk of lung cancer or other pulmonary diseases. Chuang et al. [19] investigated emissions from different types of candles and incense and their health implications in an Anglican church in the United Kingdom. The generation and subsequent inhalation of particles during church activities was found to pose significant respiratory health risks. It was revealed that during the burning of candles and incense the relative respiratory exposure risk connected with the emitted particles was higher than in the case of tobacco particles.

The present study is a continuation of the research carried out by Polednik [8] in a Baroque
Roman Catholic church in Poland and reports aerosol particle number and mass concentration changes inside the church and outdoors during three ordinary Masses with special consideration given to the manner of submicrometer particle emissions as well as the indoor microclimate and outdoor weather conditions.

\section{MATERIALS AND METHODS}

\section{Measurement site}

Particle number and mass concentrations were measured in the Roman Catholic church in Urzedow near Lublin in eastern Poland. A detailed description of the church has been presented elsewhere by Polednik [8]. In short, it is a brick-built gravitationally ventilated Baroque church with stained-glass windows. The church floor plan with an indication of the sampling instrument locations is shown in Figure 1. The instruments for indoor measurements were placed in the left altar at the height of about $1.3 \mathrm{~m}$ and about $6.5 \mathrm{~m}$ away from the main altar. The instruments for outdoor measurements were set up outside one of the front windows at the height of approximately $5 \mathrm{~m}$. The church windows were closed during the measurement period.

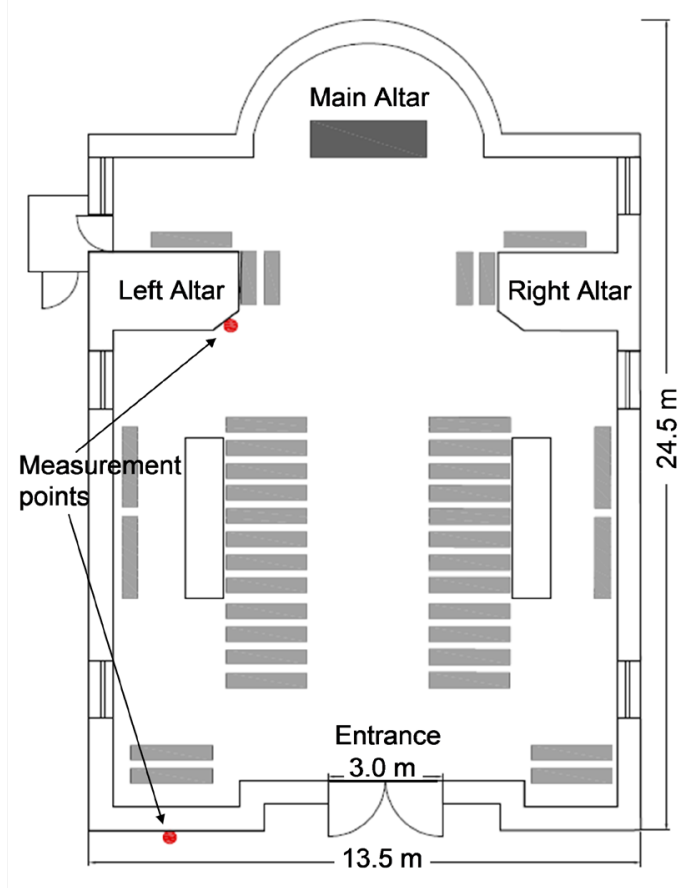

Figure 1. The church floor plan with sampling instrument locations. 


\section{Monitoring instruments}

Particle concentrations were simultaneously measured inside the church and outdoors. The number concentrations of particles with the size ranging from 0.02 to about $1 \mu \mathrm{m}\left(\mathrm{PN}_{<1}\right)$ were determined with the use of ultrafine particle counters P-Trak model 8525 (TSI Inc., USA). The number concentrations and size distribution of particles greater than $0.3 \mu \mathrm{m}\left(\mathrm{PN}_{0.3-0.5}, \mathrm{PN}_{0.5-1}\right.$, $\mathrm{PN}_{1-2}, \mathrm{PN}_{2-5}, \mathrm{PN}_{5-10}$ and $\mathrm{PN}_{>10}$ ) were measured using optical spectrometers OPS 3330 (TSI Inc., USA). Particle mass concentrations were measured using aerosol monitors DustTrak DRX model 8533 (TSI Inc., USA) which determined the approximations of mass concentrations of $\mathrm{PM}_{1}, \mathrm{PM}_{2.5}, \mathrm{PM}_{10}$, RESP and TSP (particles with an aerodynamic diameter equal or less than $1,2.5$, $10 \mu \mathrm{m}$, respirable and total suspended particles, respectively). DustTrak monitors were subject to the standard real-time size correction factor calibration. The obtained particle mass concentrations were not actual gravimetric values, but only their approximations. While discussing the DustTrak results, the term "approximation" is not used for simplification purposes. All instruments were calibrated by their manufacturer at the beginning of the measurements. The logging interval for the instruments was 1 minute. Due to a power failure during Mass M2 the measurement results recorded for this Mass are only partial and do not include all number and mass concentrations of all the considered particle sizes.

\section{Monitoring methods}

Continuous particle concentration measurements inside the church and outdoors were conducted for one Sunday (M1) and two weekday Masses (M2, M3). During each Mass three candles were burned at the main altar and the incense was used in the main altar area. The candles were lit just before the Mass and put out at the end of each Mass. Incense of a comparable burning intensity was applied at similar stages of each Mass. In the case of the third monitored Mass (M3) the incense was lit twice during the Mass.

The Masses were held at different times of the day. The Sunday Mass M1 with 170 participants and the weekday Mass M2 (about 150 participants) were held in the afternoon and lasted for about 60 minutes. Approximately 160 persons participated in the weekday evening Mass M3 which lasted for about 60 minutes. A 30-minute celebration attended by a smaller number of participants took place before Mass M3, and a certain number of people stayed in the church after the Mass to help clean the church. Indoor microclimate and outdoor weather parameters during Masses are presented in Table 1. Average indoor air temperatures during Mass M1, M2 and M3, respectively amounted to $16.5,18.5$ and $15^{\circ} \mathrm{C}$ while the relative humidity was at the average level of 66,63 and $79 \%$, respectively. The outdoor weather conditions during the individual Masses were as follows: Mass M1 was held on a cloudy day, without rainfall and with the outdoor temperature of approximately $17^{\circ} \mathrm{C}$ and relative humidity of

Table 1. Indoor microclimate and outdoor weather parameters during Masses in the church

\begin{tabular}{|c|c|c|c|}
\hline \multirow{2}{*}{ Specification } & & Mass & \\
\hline & M1 & M2 & M3 \\
\hline \multirow{2}{*}{ Day } & Sunday & Friday & Thursday \\
\hline & 13.06.2012 & 08.06 .2012 & 14.06 .2012 \\
\hline Time & $14: 30-15: 30$ & $15: 00-16: 00$ & $18: 30-19: 30$ \\
\hline $\begin{array}{rr}\text { Outdoor T } & {\left[{ }^{\circ} \mathrm{C}\right]} \\
\text { and } \mathrm{RH} & {[\%]}\end{array}$ & $\begin{array}{c}16.7-16.4 \\
63-64 \\
\end{array}$ & $\begin{array}{c}22.5-22.1 \\
48-49 \\
\end{array}$ & $\begin{array}{c}13.0-12.9 \\
99-100\end{array}$ \\
\hline $\begin{array}{rr}\text { Indoor } \mathrm{T} & {\left[{ }^{\circ} \mathrm{C}\right]} \\
\text { and } \mathrm{RH} & {[\%]}\end{array}$ & $\begin{array}{c}16.2-16.3 \\
65-67 \\
\end{array}$ & $\begin{array}{c}18.4-18.6 \\
63-64 \\
\end{array}$ & $\begin{array}{c}15.2-15.2 \\
78-79 \\
\end{array}$ \\
\hline Air pressure [hPa] & $1001.4-1001.2$ & $1006.1-1006.2$ & $994.4-994.2$ \\
\hline $\begin{array}{l}\text { Weather } \\
\text { conditions }\end{array}$ & $\begin{array}{c}\text { Cloudy } \\
\text { Light winds }\end{array}$ & $\begin{array}{l}\text { Sunny } \\
\text { Calm }\end{array}$ & $\begin{array}{l}\text { Heavy rain } \\
\text { Windy }\end{array}$ \\
\hline
\end{tabular}

$\mathrm{T}$ - air temperature; $\mathrm{RH}$ - air relative humidity. 
$63 \%$, it was mostly sunny during Mass M2 with the average outdoor air temperature of about $22^{\circ}$ $\mathrm{C}$ and relative humidity of $48 \%$, while Mass M3 was held on a rainy day (with heavy rain during the time of the Mass) with the temperature not exceeding $13{ }^{\circ} \mathrm{C}$ and relative humidity of $100 \%$.

\section{Calculation methods}

The measured particle concentrations were used to estimate the time-integrated particle exposure. A simple mass balance model ${ }^{20}$ was applied and the amount of particles inhaled by the churchgoers during the Mass was determined from the equation (1):

$$
D=B \frac{P}{\lambda}\left(t+\frac{1}{\lambda}\left(e^{-\lambda t}-1\right)\right)
$$

where: $\mathrm{B}$ is the breathing frequency $\left(12 \times 10^{3} \mathrm{~cm}^{3} /\right.$ $\min ), P$ is the particle concentration increase rate $\left(\mathrm{pt} / \mathrm{cm}^{3} \mathrm{~min}\right), \lambda$ is the particle decrease rate constant $(1 / \mathrm{min})$, and $t$ is the time elapsed during the Mass (min).

The particle concentration increase rates and decrease rate constants were determined separately for each Mass. The average particle concentration in the period before the given Mass was considered as a background value and was subtracted from the measured data. The particle concentration increase rate was calculated by fitting the data obtained during the Mass to the formula (2):

$$
C=\frac{P}{\lambda}\left(1-e^{-\lambda t}\right)
$$

where: $C$ is the particle concentration $\left(\mathrm{pt} / \mathrm{cm}^{3}\right)$.

The particle decrease rate constants which incorporate particle losses predominantly resulting from the church ventilation, exfiltration and deposition of particles were calculated by fitting the results obtained after the end of the Mass to a first-order exponential function (3):

$$
C=C_{p} e^{-\lambda t_{e}}
$$

where: $C_{p}$ is the particle concentration determined at the end of the Mass $\left(\mathrm{pt} / \mathrm{cm}^{3}\right), t_{e}$ is the time elapsed since the end of the Mass.

All data analyses were performed for indoor and outdoor particle concentrations grouped according to the Mass services in the church. Descriptive statistics were applied to characterize the particle concentration changes. Particle exposure inside the church during the Masses as well as outdoors was determined with the application of the nonlinear regression technique.

\section{RESULTS}

The results of measurements performed during the Masses in the church were presented to demonstrate the relationship between the particle concentration levels, the dynamics of their changes and the intensity of the particle generating sources e.g. the presence and activity of the churchgoers. Particular focus was placed on other factors that so far have not been typically examined such as the manner of the particle emissions and the outdoor weather conditions.

The time series of the particle number and mass concentrations of selected size fractions measured inside the church and outdoors during Mass M1 held on a cloudy day and M3 held on a rainy day are presented in Figure 2 and Figure 3, respectively. The time series of the particle concentrations during Mass M2 held on a sunny day have not been presented due to incomplete data resulting from the measurement instrument failure.

Particle concentration levels in the church mostly depend on the intensity of the particle sources and the rate of eliminating particles from the indoor air. The average concentrations of all the particles measured in the church during the monitored Masses with a similar number of participants were significantly higher than the levels recorded outside the church. During the Masses the greatest increases in the concentrations of all the considered particles were observed upon the commencement of the incense use. It needs to be emphasized, however, that the manner of the particle emissions in the church which was essentially related to the number of times the incense was used during the Mass had a material impact on the increments of particle concentrations. It can be seen on the examples of the variations of particle number and mass concentrations during Mass M3, at which the incense was used twice.

It is also worth noting that during Mass M1 the increases in the number concentrations of finer particles occurred prior to the observed increases in the number concentrations of coarser particles. During that Mass the $\mathrm{PN}_{1}$ concentration increased about 16 times, the concentration of $\mathrm{PN}_{2-5}$ increased around 50 times, while the concentra- 


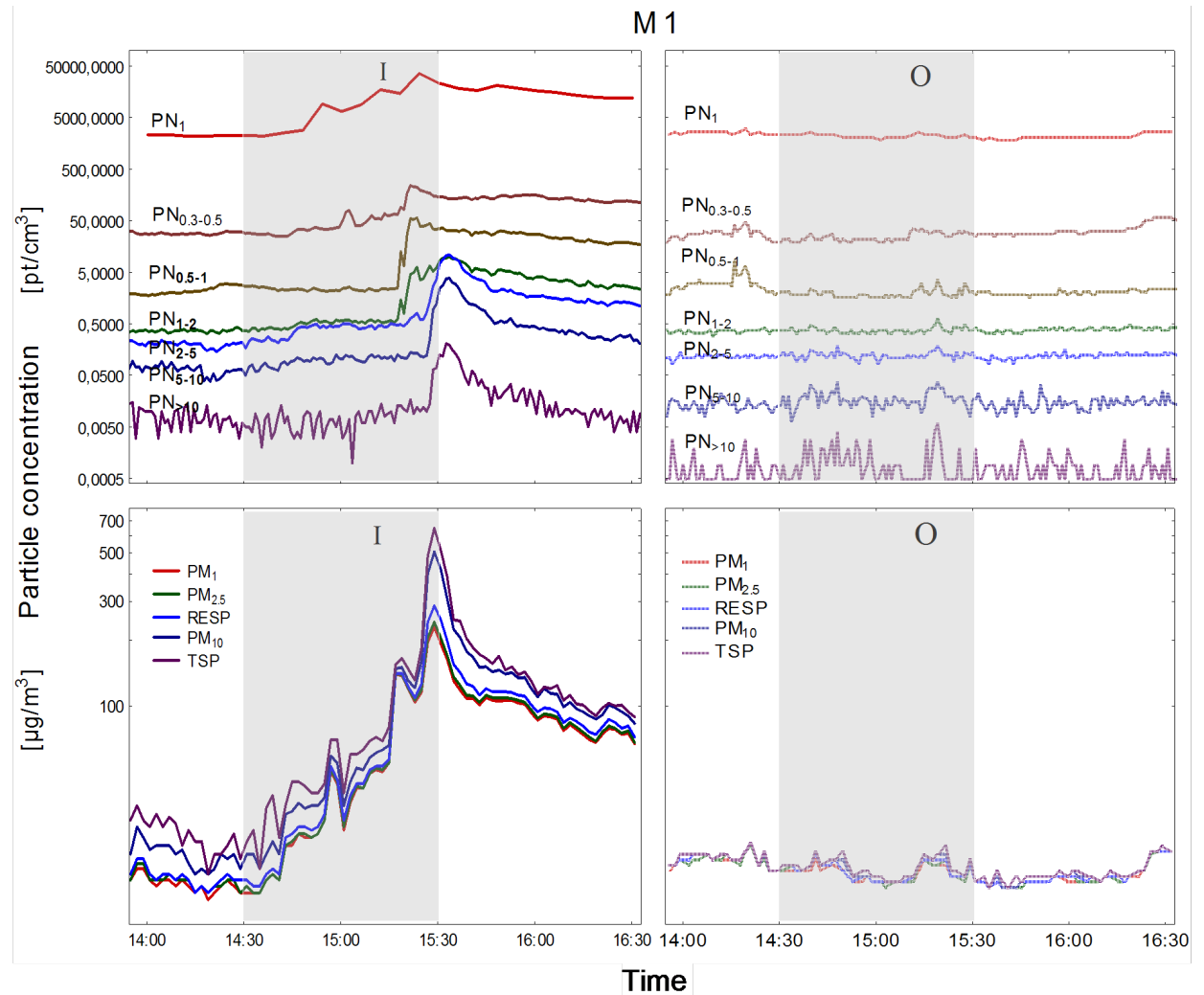

Figure 2. Time series of the indoor and outdoor particle number and mass concentrations during Mass M1 held on a cloudy day. PN - particle number, PM - particle mass; the indices represent the particle size fractions, TSP - total suspended particles.

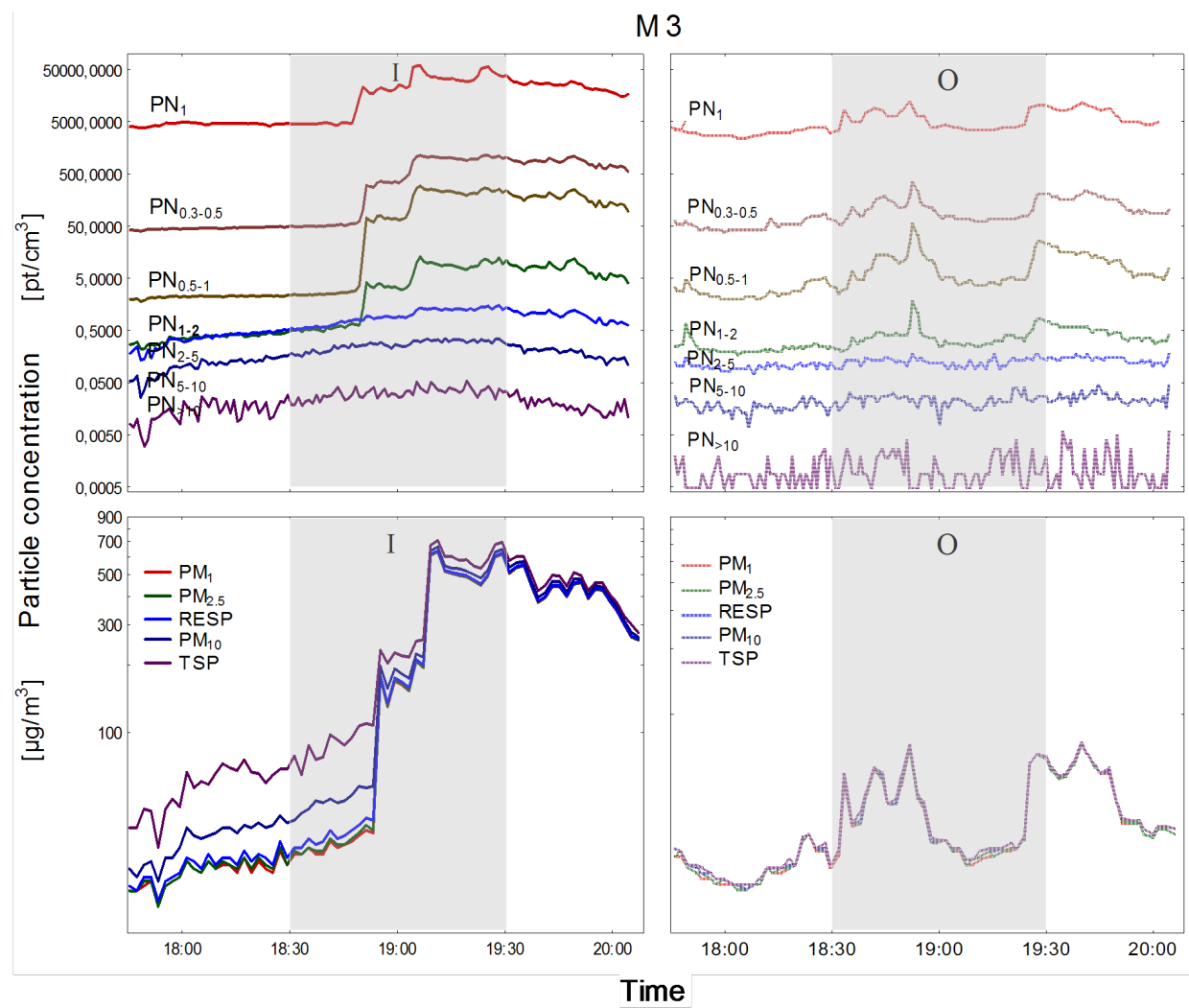

Figure 3. Time series of the indoor and outdoor particle number and mass concentrations during the Mass M3 held on a rainy day. PN - particle number, PM - particle mass; the indices represent the particle size fractions, TSP - total suspended particles. 
tion of coarse particles $\mathrm{PN}_{>10}$ increased around 69 times. The maximum concentration increments of the above-indicated particles occurred at the end of the Mass and amounted to about 3.6 $10^{3}, 4$ and $0.1 \mathrm{pt} / \mathrm{cm}^{3} \mathrm{~min}$ while their concentrations reached the respective levels of $36.1 \cdot 10^{3}, 11$ and $0.2 \mathrm{pt} /$ $\mathrm{cm}^{3}$. In the case of Mass $\mathrm{M} 3$ the $\mathrm{PN}_{1}, \mathrm{PN}_{2-5}$ and $\mathrm{PN}_{>10}$ concentrations reached the respective levels of $59.4 \cdot 10^{3}, 15$ and $0.05 \mathrm{pt} / \mathrm{cm}^{3}$ which were respectively about 15,10 and 7 times higher than the church background levels recorded before the start of the Mass. The maximum concentration increments were measured during the first incense use and amounted to about $15.6 \cdot 10^{3}, 0.2$ and 0.02 $\mathrm{pt} / \mathrm{cm}^{3} \mathrm{~min}$, respectively.

Increases of particle mass concentrations were observed from the very beginning of the Masses and their various intensity was recorded until the end of each Mass.

Particle concentration increases differed depending on the particle size. During Mass M1 the mass concentration of the finest measured particles $\mathrm{PM}_{1}$ increased about 18 times, the concentration of coarse particles $\mathrm{PM}_{10}$ about 29 times and the mass concentration of total particles suspended in the indoor air (TSP) increased almost 38 times. The maximum concentration increments of these particles were observed at the end of the Masses and amounted to 40,121 and $151 \mu \mathrm{g} / \mathrm{m}^{3} \mathrm{~min}$ respectively, reaching the respective concentration levels of 229, 506 and $650 \mu \mathrm{g} /$ $\mathrm{m}^{3}$. During Mass M3 the concentrations of $\mathrm{PM}_{1}$, $\mathrm{PM}_{10}$ and TSP reached the levels of 632, 665 and $709 \mu \mathrm{g} / \mathrm{m}^{3}$ which were respectively about 39 , 35 and 27 times higher than the church background levels recorded before the start of the Mass. The maximum particle mass concentration increments were observed during the first incense use and amounted to about 210, 209 and $207 \mu \mathrm{g} / \mathrm{m}^{3} \mathrm{~min}$, respectively.

The time series of the submicrometer particle number concentrations $\mathrm{PN}_{1}$ and mass concentrations $\mathrm{PM}_{1}$ inside the church and outdoors during each of the considered Masses are presented in Figure $4 a$ and $4 b$.

Statistical information about the indoor and outdoor $\mathrm{PN}_{1}$ and $\mathrm{PM}_{1}$ concentrations and their a

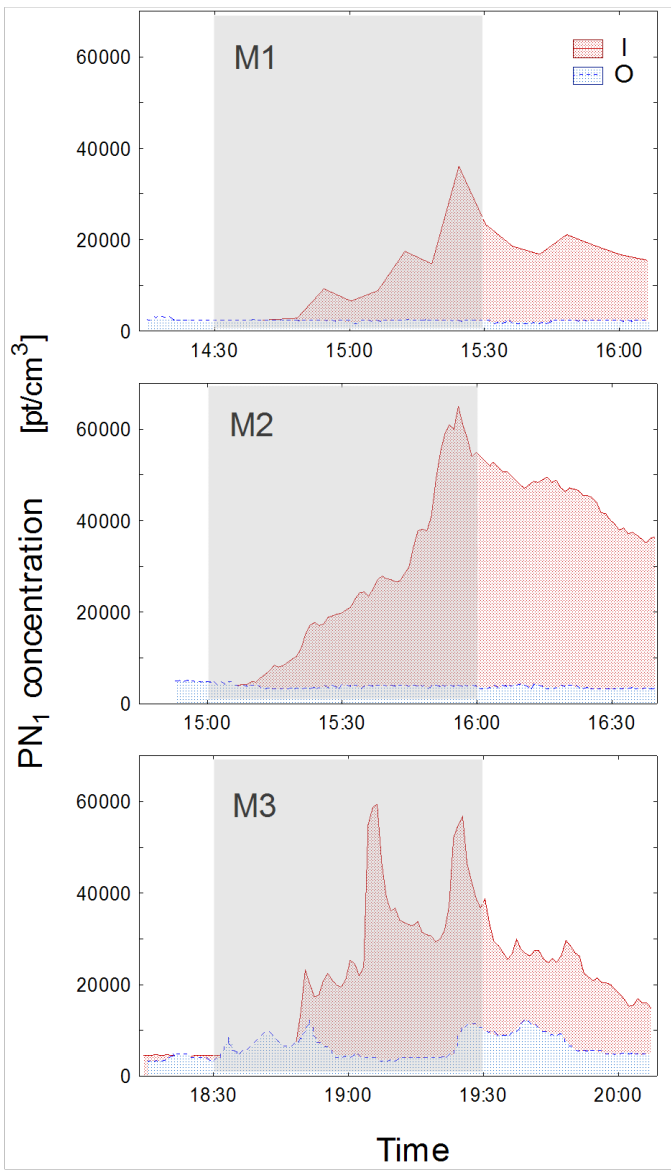

b
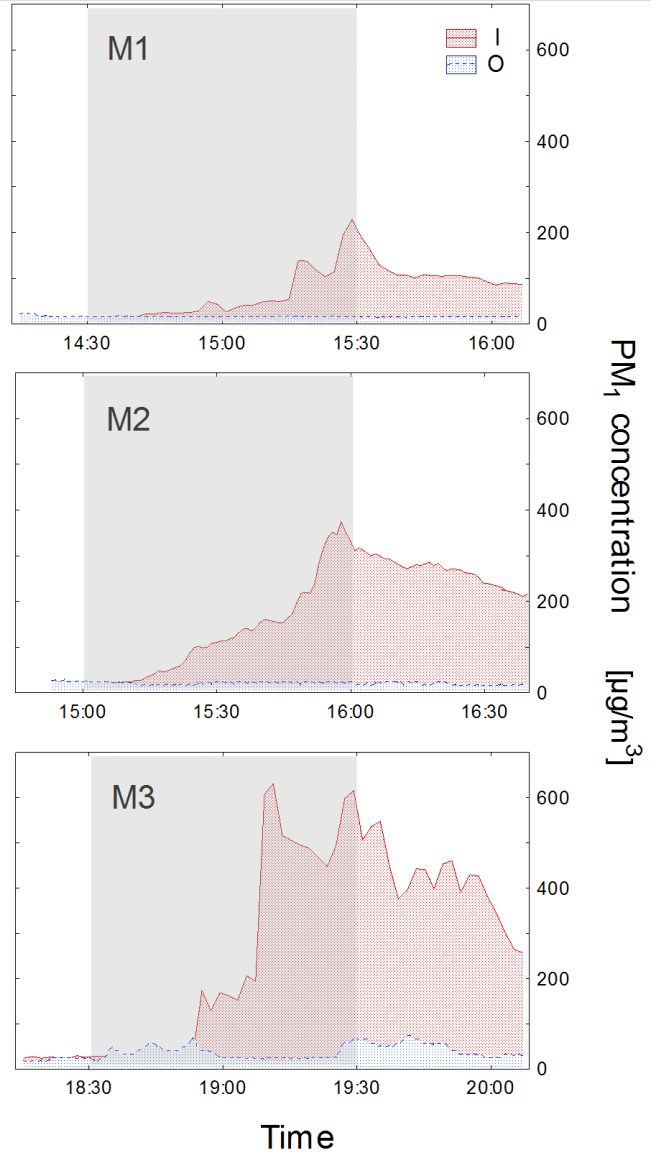

Figure 4. Time series of the concentration of particles $\mathrm{a}-\mathrm{PN}_{1}$ and $\mathrm{b}-\mathrm{PM}_{1}$ in the church and outdoors during Masses M1, M2 and M3. 
indoor to outdoor $(\mathrm{I} / \mathrm{O})$ ratios during each of the monitored Mass are presented in Table 2.

The greatest average concentrations of $\mathrm{PN}_{1}$ and $\mathrm{PM}_{1}$ amounting to $23.9(16.9) \cdot 10^{3} \mathrm{pt} / \mathrm{cm}^{3}$ and $241.1(230.7) \mu \mathrm{g} / \mathrm{m}^{3}$ were recorded during Mass M3 at which the incense was used twice and which was held during heavy rainfall (the values in brackets represent standard deviations). Maximum $\mathrm{PM}_{1}$ concentration levels of up to $632 \mu \mathrm{g} / \mathrm{m}^{3}$ were also measured during that Mass. In the case of Mass M1 and M2 at which the incense was used once and during which the weather outdoors was respectively cloudy and sunny, the average $\mathrm{PN}_{1}$ amounted to $9.0(10.0) \cdot 10^{3}$ and $23.7(18.3)$ $\mathrm{x} 10^{3} \mathrm{pt} / \mathrm{cm}^{3}$ while the average $\mathrm{PM}_{1}$ concentrations amounted to 53.9(57.5) and 127.1(102.3) $\mu \mathrm{g} / \mathrm{m}^{3}$, respectively. The maximum $\mathrm{PN}_{1}$ concentration amounting to about $65.0 \cdot 10^{3} \mathrm{pt} / \mathrm{cm}^{3}$ was recorded during M2.

The maximum $\mathrm{PN}_{1}$ concentration increments during M1, M2 and M3 amounted to about $3.6 \mathrm{v} 10^{3}, 8.0 \cdot 10^{3}$ and $15.6 \mathrm{v} 10^{3} \mathrm{pt} / \mathrm{cm}^{3} \mathrm{~min}$ and their number concentrations in the church reached the respective levels of $36.1 \cdot 10^{3}, 65.0 \cdot 10^{3}$ and $59.4 \cdot 10^{3} \mathrm{pt} / \mathrm{cm}^{3}$. The maximum $\mathrm{PM}_{1}$ concentration increments amounted to about 40,47 and 210 $\mu \mathrm{g} / \mathrm{m}^{3} \mathrm{~min}$ and their particle mass concentrations in the church reached the respective levels of 229 , 375 and $632 \mu \mathrm{g} / \mathrm{m}^{3}$.

The variability of $\mathrm{PN}_{1}$ and $\mathrm{PM}_{1}$ concentration increments during the Masses in the church are presented in Figure $5 \mathrm{a}$ and $5 \mathrm{~b}$. The fluctuations were characterized by the empirical cumulative distribution functions (ECDFs) smoothed using locally weighted regressions (LOWESS). The ECDFs slopes demonstrate the ranges of $\mathrm{PN}_{1}$ and $\mathrm{PM}_{1}$ concentration changes that were observed during the individual Masses. Steep functions observed for Masses M1 and M2 indicate that the narrow range of increments of $\mathrm{PN}_{1}$ and $\mathrm{PM}_{1}$ concentrations was overrepresented in the obtained measurement results. A more gradual increase of the functions which can be seen in the case of Mass M3 are symptomatic for a broader range of increments of such particle concentrations. A symmetry of the cumulative distributions with respect to the zero concentration increments would indicate an equability of positive and negative particle concentration increments. The above would basically mean that the particle concentration increases would be balanced by particle concentration decreases, and therefore that the same quantities of particles would be produced and removed during the Mass. The obtained asymmetric ECDFs of concentration variations of the considered submicrometer particles indicate the prevalence of positive concentration increments which are associated with the domination of such particle delivery processes during the Masses in the church.

Particle number and mass concentrations of submicrometer particles measured in the church during the Masses significantly exceeded their corresponding outdoor levels. The highest average indoor to outdoor ratio for $\mathrm{PN}_{1}$ concentrations was recorded during M2 and amounted to 6.3(4.9), with the maximum value of 17.3. In turn, the highest average indoor to outdoor ratio for $\mathrm{PM}_{1}$ concentrations was determined during M3 and amounted to 9.6(10.2), with the maximum value of 26.3 .

Figure 6 presents the estimated amount of submicrometer particles inhaled by an average churchgoer during the individual Masses in the church as well as the amounts that would be inhaled by an average Mass participant if he/she stayed outdoors during the same period of time.

Table 2. Descriptive statistics for submicrometer particle number $\left(\mathrm{PN}_{1}\right)$ concentrations $\left(\mathrm{in} \times 10^{3} \mathrm{pt} / \mathrm{cm}^{3}\right)$ and particle mass $\left(\mathrm{PM}_{1}\right)$ concentrations (in $\left.\mu \mathrm{g} / \mathrm{m}^{3}\right)$ indoors $(\mathrm{I})$ and outdoors $(\mathrm{O})$ and for their indoor to outdoor (I/O) ratios during the individual Masses in the church.

\begin{tabular}{|c|c|c|c|}
\hline \multirow{2}{*}{ Mass } & $\mathrm{I}$ & $\mathrm{O}$ & $\mathrm{I}$ \\
\cline { 2 - 4 } & \multicolumn{3}{|c|}{$\mathrm{PN}_{1}$} \\
\hline M1 & $9.0 / 4.7(2.2-36.1)[1.11]$ & $2.3 / 2.3(2.1-2.7)[0.08]$ & $4.0 / 2.2(0.9-16.8)[1.15]$ \\
\hline M2 & $23.7 / 19.8(3.9-65.0)[0.77]$ & $3.8 / 3.8(3.4-4.7)[0.08]$ & $6.3 / 5.4(0.8-17.3)[0.77]$ \\
\hline M3 & $23.9 / 22.5(4.3-59.4)[0.71]$ & $6.1 / 4.6(3.4-11.9)[0.43]$ & $4.8 / 3.8(0.5-14.4)[0.85]$ \\
\hline \multicolumn{4}{|c|}{$\mathrm{PM}_{1}$} \\
\hline M1 & $53.9 / 26.5(13.0-229.0)[1.06]$ & $17.3 / 17.0(15.0-20.0)[0.08]$ & $3.2 / 1.6(0.8-14.3)[1.12]$ \\
\hline M2 & $127.1 / 111.0(22.2-374.9)[0.80]$ & $21.4 / 21.2(18.9-26.5)[0.08]$ & $6.0 / 5.3(0.8-17.7)[0.80]$ \\
\hline M3 & $241.1 / 163.0(26.0-632.0)[0.96]$ & $32.2 / 26.0(20.0-70.0)[0.39]$ & $9.6 / 4.0(0.6-26.3)[1.06]$ \\
\hline
\end{tabular}

Arithmetic average/median (range) [coefficient of variation]. 


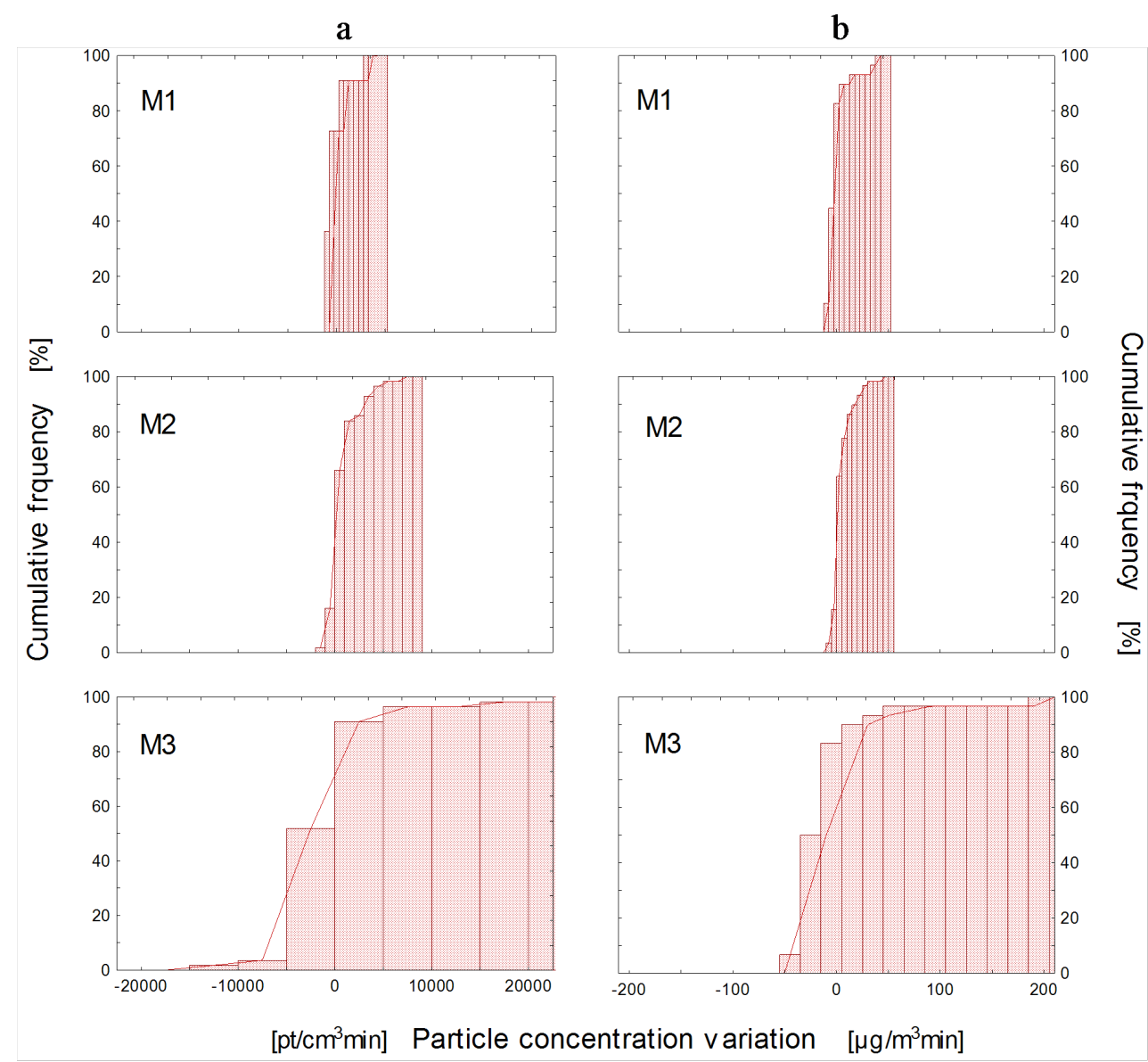

Figure 5. Empirical cumulative distribution functions (ECDFs) of a $-\mathrm{PN}_{1}$ and $\mathrm{b}-\mathrm{PM}_{1}$ concentration variations during Masses M1, M2 and M3 in the church.

The greatest number of submicrometer particles i.e. about $18.5 \cdot 10^{9}$ was inhaled by an average Mass M2 participant and it was approximately 7 times higher than the number that would have been inhaled outdoors. An average participant of Masses M1 and M3 inhaled about $8.3 \cdot 10^{9}$ and $16.1 \cdot 10^{9}$ particles, respectively which values were about 4 times higher than the values that would have been inhaled outdoors in the same period of time.

The greatest mass of submicrometer particles i.e. about $195.4 \mu \mathrm{g}$ was inhaled by an average Mass M3 participant and it was approximately 8 times higher than the mass of particles that would have been inhaled outdoors during the same time. An average participant of Masses M1 and M2 inhaled about $44.3 \mu \mathrm{g}$ and $89.8 \mu \mathrm{g}$ of particles, respectively which were about 3 and 7 times higher than the amounts that would have been inhaled outdoors in the same period of time.

The number and mass concentrations of all the measured particle fractions gradually decreased after the end of each Mass and ultimately reached their church background levels. Concentrations of coarser particles generally decreased faster than the concentrations of finer particles.

\section{DISCUSSION}

This study demonstrates the variations of indoor particle concentrations during Masses in a church and attempts to interconnect them with the changes of the indoor microclimate and outdoor weather conditions as well as the manner of the particle emissions.

As in the previously carried out research in the monitored church the Mass participants and their physical activity as well as the burning of candles and the incense were the main indoor particle sources [8]. The physical activity of the churchgoers contributed mainly to the increases of coarser aerosol particle concentrations in the church while the burning processes were responsible for the increases of fine and ultrafine particle concentrations. In the case of the physical activ- 
a

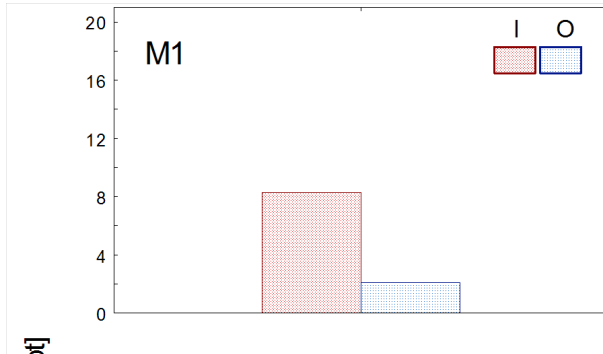

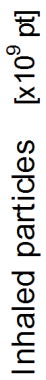

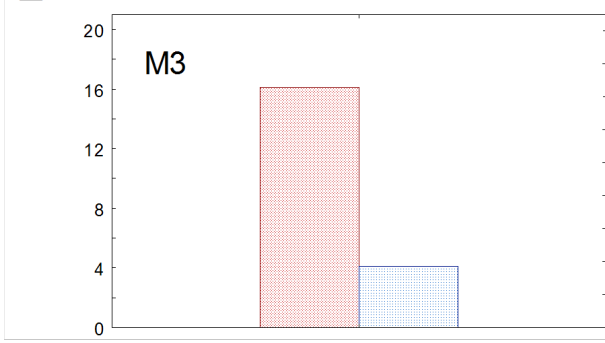

b
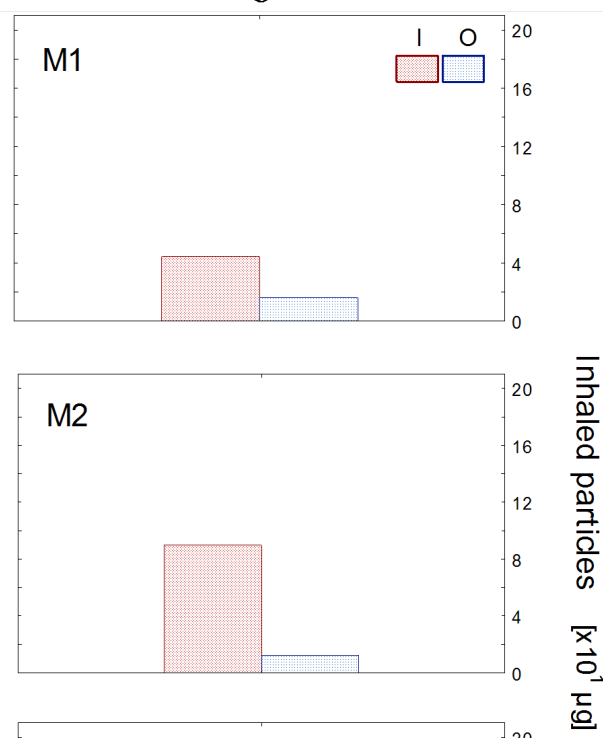

Figure 6. Amount of submicrometer particles inhaled by an average churchgoer during the individual Masses (M1, M2, M3) in the church (I) and outdoors (O); a - number of inhaled particles (in pt), b - mass of inhaled particles (in $\mu \mathrm{g}$ ).

ity of the churchgoers, the intensity of the particle emissions mainly depended on the number of the churchgoers, while in the case of the burning processes, the number of the lit candles and the incense burning was of significance. The highest particle number and mass concentrations were observed when both candles were lit and the incense was burned. The increments of particle number and mass concentrations in the church during the Masses resulted from the changes of the conditions both inside the church and outdoors. Not only the intensity of particle generating sources but also the manner of their emissions were of significance. The outdoor conditions such as the air temperature, humidity and rain had an impact on the church ventilation which, in turn, had a significant impact on the concentration of particles suspended in the indoor air. The outdoor conditions also impacted the indoor particle formation and growth processes which along with the aggregation and deposition contributed to the changes of indoor particle size distributions. Average indoor submicrometer particle number concentrations and the number of such particles inhaled by an average Mass participant were on similar levels during Masses which were held on two entirely different days in terms of the weather i.e. on a sunny and a rainy day and they were higher than during the Mass which took place on a cloudy day. Average indoor submicrometer particle mass concentrations and the mass of such particles inhaled by an average participant of the Mass held on a rainy day were higher than during the Masses that took place on the other two rain-free days.

The presented findings can be interpreted with the consideration of the knowledge about aerosol particles taking into account the dynamics of their generation, transformation and dispersion both in the indoor and outdoor environment. The manner of particle emissions had the greatest impact on the measurements carried out during the Mass held on a rainy day i.e. the fact that the incense was used twice during that Mass. A larger number of submicrometer particles was emitted at that time which resulted in an obvious increase of such particle concentration in the church. The indoor and outdoor conditions also impacted the measurement results obtained during all the considered Masses. 
Outdoor weather conditions such as the outdoor air temperature, humidity, rain, air pressure, wind speed and its direction surely had an impact on the church ventilation which, in turn, had a significant impact on the concentration of particles suspended in the indoor air [21-23]. Furthermore, atmospheric processes of nucleation, coagulation and condensation could also be of significance as they lead to the changes of the size and size distributions of outdoor particles which are more intensive at increased ambient air humidity observed on rainy days. Fuzzi et al. [24] and Davis et al. [25] reviewed the most recent literature on such atmospheric processes, including their impact on the human health. As shown in many laboratory studies, elevated humidity levels enhance aerosol formation [26, 27]. The above is also confirmed by numerous field studies. For example Gao et al. [28] revealed that the sizes of aerosol particles increase due to moisture absorption under high humidity conditions. Silva et al. [29] described the aerosol particle hygroscopic growth dependent on the atmospheric electric field. The research on the interactions between air pollution and humidity demonstrated that on days with relatively high humidity, heterogeneous formations of secondary aerosols by gas-to-particle conversion processes are substantial $[30,31]$. In turn, $\mathrm{Vu}$ et al. [32] while characterizing the number size distributions of particles from major urban sources revealed that the course and intensity of the nucleation, coagulation and condensation processes that have a strong influence on the particle number size distributions are to a significant extent dependent on the air humidity.

In the case of indoor conditions, indoor particle formation/growth processes could have had a certain impact on the obtained results as, according to the literature, they are largely affected by ambient meteorological conditions. For example Hirsikko et al. [33] reported increases in concentration of ions responsible for the growth of particles and new-particle formation processes indoors during the rain. Particle formation processes together with the aggregation and deposition processes described by e.g. Nazaroff [34] and the rain-related infiltration of particles can change the indoor particle size distributions. The research carried out by Chithra and Shiva [35] in a naturally ventilated classroom which indicated a significant impact of outdoor meteorological conditions on particle mass concentrations is also of relevance in this respect.
The results obtained during the Mass held on a rainy day could also be impacted by the increase of the indoor air relative humidity caused by the presence of additional water vapor sources inside the church such as e.g. wet floor as well as wet shoes, clothes and umbrellas of the Mass participants. The significance of the indoor air humidity level may be confirmed by e.g. research demonstrating rapid increases in indoor VOC concentrations (a precursor of organic aerosols) along with the increases of indoor humidity [36]. This, in turn, results in more intensive VOC-particle interactions [37]. The above might to a certain extent have contributed to relatively high levels of mass particle concentrations and low average particle number concentrations which were observed during that Mass.

The influence of outdoor particles on indoor particle concentrations does not seem to be significant in the case of Masses held on a cloudy and on a sunny day. However, such particles could have had some impact in the case of the Mass held on a rainy day. Similarly to the research carried out by Hussain et al. [38], the time-varying outdoor particle concentrations observed during the Mass which was held on a rainy day could have had a stronger influence on indoor particle concentrations. One possible reason for the relatively high outdoor particle concentration changes during that Mass which were observed mainly at the beginning and end of the Mass was a greater number of cars parked outside the church on that day and the resulting increased car traffic.

As observed in other studies [12,19], after the end of the Mass the submicrometer particle concentration decrease rate was mostly impacted by their deposition processes on indoor surfaces, aggregation processes into coarser particles and ventilation conditions which changed as a result of e.g. opening the church door. As for coarser particles, the concentration decrease rate was affected by the physical activity of the churchgoers who exited the church after the Mass. Such activity resulted in increased air circulation which hindered the deposition of such particles. It may have also led to the resuspension of the already deposited particles.

The obtained results concerning the particle concentration levels are in agreement with the results reported in previous research in several churches in Europe in which both candles were lit and incense was burned. The research carried out in a Catholic church in Germany showed that 
during Masses candle burning had only little effect on the measured particle concentrations as compared to incense burning [15]. The average $\mathrm{PM}_{1}$ and $\mathrm{PM}_{10}$ concentrations increased 9.1 and 6.9 times and respectively amounted to $64.7 \mu \mathrm{g} /$ $\mathrm{m}^{3}$ and $85.3 \mu \mathrm{g} / \mathrm{m}^{3}$. The maximum concentrations of such particles were elevated by a factor of 23.1 and 20.3 above the background levels. Comparable results were obtained during a Mass in an Anglican church in the UK [19]. The average $\mathrm{PM}_{2.5}$ and $\mathrm{PM}_{10}$ concentrations amounted respectively to $38.9 \mu \mathrm{g} / \mathrm{m}^{3}$ and $91.6 \mu \mathrm{g} / \mathrm{m}^{3}$. In the case of the latter, the concentrations were 7.2 times higher than outdoors. Increases of particle concentrations were observed to take place very quickly after the candles and the incense had been lit. Furthermore, a large amount of particles was recorded several minutes after extinguishing the combustion sources. Due to limited ventilation, it took up to several hours after the Mass for the particle concentrations to return to their background levels. During such time finer suspended particles appeared to coagulate into coarse agglomerative particles due to the changes of the indoor air thermal parameters (i.e. temperature and humidity). The concentration of $\mathrm{PM}_{10}$ measured in a Roman Catholic church in the Netherlands reached the level of $658 \mu \mathrm{g} / \mathrm{m}^{3}$ which was 12.4 times higher than the outdoor values [18]. In a small chapel in that church such particle concentrations exceeded $1000 \mu \mathrm{g} / \mathrm{m}^{3}$ and were over 19 times higher than the concentrations recorded in high-traffic outdoor locations. In turn, measurements performed in Orthodox churches in Cyprus showed that average concentrations of $\mathrm{PM}_{0.3-10}$ reached the values of 500 $\mu \mathrm{g} / \mathrm{m}^{3}$ and the highest concentrations of $\mathrm{PM}_{0.5-1}$ were 10.7 times higher than outdoors. ${ }^{12}$ Similar mass concentration levels were also recorded in temples in Asia during religious ceremonies at which incense was burned. $\mathrm{PM}_{10}$ concentrations in a Buddhist-Taoist temple in Taiwan ranged from 44.8 to $257.2 \mu \mathrm{g} / \mathrm{m}^{3}$ [39]. Higher concentrations were measured in Taoist temples in Hong Kong [40]. In one of the monitored temples during the peak period in which a greater number of pilgrims appeared for blessing the highest $\mathrm{PM}_{2.5}$ and $\mathrm{PM}_{10}$ concentrations reached respectively the levels of 1300 and $1500 \mu \mathrm{g} / \mathrm{m}^{3}$. Particle number concentrations recorded in temples in China [41] were similar to the levels reported in this paper. For example, the mean number concentrations of $\mathrm{PN}_{0.3-0.5}$ in the worship room during peak periods ranged between 214 and $239 \mathrm{pt} / \mathrm{cm}^{3}$.
The increments of submicrometer particle concentrations recorded during incense burning roughly correspond to the emission rates of aerosol particles due to other indoor activities. For example Hussein et al. [38] estimated that burning wood and grilling in a fireplace can produce as much as $200 \mathrm{pt} / \mathrm{cm}^{3} \mathrm{~s}$. The estimated exposure to particulate matter of the individual Mass participants is comparable to the data found in literature concerning the amount of inhaled particles during such activities as cooking, frying, or staying outdoors in a large polluted city center. For example, the contribution of $20 \mathrm{~min}$ frying to an individual's typical exposure to particulate matter reported by Evans et al. [20] amounted to $1.7 \cdot 10^{10}$ of ultrafine particles and $50 \mu \mathrm{g}$ of $\mathrm{PM}_{2.5}$. Based on the research carried out by Jeong et al. [42] the amounts of particles inhaled by individuals staying outdoors in downtown Toronto for $1 \mathrm{~h}$ on a polluted day amounted to $1.8 \cdot 10^{10}$ particles and $22 \mu \mathrm{g}$ of $\mathrm{PM}_{2.5}$.

Further detailed research is required on the quality of indoor air deteriorated by the presence of particles generated during religious services in churches. Special focus should be placed on the indoor microclimate and outdoor weather conditions affecting the indoor particle concentration levels. Research on the changes of the chemical and biological properties of such particles would also be beneficial as they have an important impact on the air quality in churches and therefore the health of the churchgoers. Activities aimed at reducing particle generation in churches by e.g. replacing traditional candles by their flameless electric versions and using incense producing less soot are also of significance. The improvement of ventilation inside churches would also be advisable.

\section{CONCLUSIONS}

Combustion activities during Masses in the church are mainly responsible for increased concentrations of submicrometer particles in the indoor air. Concentrations of these particles in the church and thus the exposure of the Mass participants depend not only on the intensity of the particle generating sources but also on the manner of their emission as well as on the indoor microclimate and outdoor weather conditions. The outdoor and indoor conditions could impact the indoor particle formation and growth which along 
with other aerosol processes could change the indoor particle size distributions.

Out of the three Masses held in the monitored church on a cloudy, sunny and rainy day with a similar number of participants during which the same number of candles were lit and incense was burned, the highest average number and mass concentrations of submicrometer particles were obtained during the Mass held on a rainy day. The greatest number of such particles was inhaled by an average participant of the Mass held on a sunny day and it was approximately 7 times higher than the number that would have been inhaled at the same time outdoors. The greatest mass of submicrometer particles was inhaled by an average participant of the Mass held on a rainy day and it was approximately 8 times higher than the mass of these particles that would have been inhaled outdoors during the same time.

The reduction of particle generating sources and effective ventilation in all weather conditions will contribute to the improvement of the indoor air quality in a church environment.

\section{Acknowledgements}

The authors would like to thank Marlena Wyrostek for the help in the measurements, the priests of the St. Nicolas church in Urzedow and the church personnel for their assistance in the research.

\section{REFERENCES}

1. Suchorab Z, Barnat-Hunek D, Smarzewski P, Pavlík Z and Černý R. Free of Volatile Organic Compounds Protection against Moisture in Building Materials. Ecol Chem Eng S 2014; 21(3), 401-411.

2. Buonanno G, Giovinco G, Morawska L and Stabile L. Lung cancer risk of airborne particles for Italian population. Environ Res 2015; 142, 443-451.

3. Polednik B. Particulate matter and student exposure in school classrooms in Lublin, Poland. Environ Res 2013; 120, 134-139.

4. Leung DYC. Outdoor-indoor air pollution in urban environment: challenges and opportunity. Front Environ Sci 2015; 2, 69, pp 7.

5. Morawska L, Afshari A, Bae GN, Buonanno G, Chao CYH, Hänninen O, Hofmann W, Isaxon C, Jayaratne ER, Pasanen P, Salthammer T, Waring M and Wierzbicka A. Indoor aerosols: from personal exposure to risk assessment. Indoor Air 2013; 23(6), 462-487.
6. Cantone L, Angelici L, Bollati V, Bonzini M, Apostoli P, Tripodi A, Bertazzi PA and Baccarelli AA. Extracellular histones mediate the effects of metal-rich air particles on blood coagulation. Environ Res 2014; 132: 76-82.

7. Hagerman I, Isaxon C, Gudmundsson A, Wierzbicka A, Dierschke K, Berglund M, Pagels JH, Nielsen J, Assarsson E, Andersson UB, Xu Y, Jönsson BAG and Bohgard $\mathrm{M}$. Effects on heart rate variability by artificially generated indoor nanosized particles in a chamber study. Atmos Environ 2014; 88: 165-171.

8. Polednik B. Particle exposure in a Baroque church during Sunday Masses. Environ Res 2013; 126 : 215-220.

9. Zanoni S, Stefani P, Ionescu G and Zambelli P. Assessing Some Criticalities Of Particulate Matter Exposure In An Urban Context. Wit Trans Ecol Environ 2014; 191: 12.

10. Ho CK, Tseng WR and Yang CY. Adverse Respiratory and Irritant Health Effects in Temple Workers in Taiwan. J Toxic Environ Health A 2005; 68(17-18): 1465-1470.

11. Pervez S, Chakrabarty R, Dewangan S, Watson JG, Chow JC, Matawle JL and Pervez Y. Cultural and Ritual Burning Emission Factors and Activity Levels in India. Aerosol Air Qual Res 2015; 15: 72-80.

12. Loupa G, Karageorgos E and Rapsomaniki S. Potential effects of particulate matter from combustion during services on human health and on works of art in medieval churches in Cyprus. Environ Pollut 2010; 158: 2946-2953.

13. Kontozova-Deutsch V, Cardell C, Urosevic M, Ruiz-Agudo E, Deutsch F and Van Grieken R. Characterization of indoor and outdoor atmospheric pollutants impacting architectural monuments: the case of San Jerónimo Monastery (Granada, Spain). Environ Earth Sci 2011; 63: 1433-1445.

14. Morabito E, Zendri E, Piazza R, Ganzerla R, Montalbani S, Marcoleoni E, Bonetto F, Scandella A, Barbante C, Gambaro A. Deposition in St. Mark's Basilica of Venice. Environ Sci Pollut R 2013; 20: 2579-2592.

15. Weber S. Exposure of churchgoers to airborne particles. Environ Sci Technol 2006; 40: 5251-5156.

16. Samek L, de Maeyer-Worobiec A, Spolnik Z, Bencs L, Kontozova V, Bratasz L, Kozlowski R and Van Grieken R. The impact of electric overhead radiant heating on the indoor environment of historic churches. J Cult Heritage 2007; 8(4): 361-369.

17. Mleczkowska A, Strojecki M, Bratasz $€$ and Kozłowski R. Particle penetration and deposition inside historical churches. Build Environ 2016; 95 : 291-298.

18. de Kok TMCM, Hogervorst JGF, Kleinjans JCS and Briede JJ. Radicals in the church. Eur Respir J 2004; 24, 1069-1070. 
19. Chuang HC, Jones T and BéruBé K. Combustion particles emitted during church services: Implications for human respiratory health. Environ Int 2012; 40: 137-142.

20. Evans GJ, Peers A and Sabaliauskas K. Particle dose estimation from frying in residential settings. Indoor Air 2008; 18: 499-510.

21. Cyrys J, Pitz M, Bischof W, Wichmann HE and Heinrich J. Relationship between indoor and outdoor levels of fine particle mass, particle number concentrations and black smoke under different ventilation conditions. J Expo Sci Environ Epidemiol 2004; 14: 275-283.

22. Zhao B and Wu J. Particle deposition in indoor environments: analysis of influencing factors. J Hazard Mater 2007; 147: 439-448.

23. Mostafa AMA, Tamaki K, Moriizumi J, Yamazawa $\mathrm{H}$ and Iida $\mathrm{T}$. The weather dependence of particle size distribution of indoor radioactive aerosol associated with radon decay products. Radiat Prot Dosimetry 2011; 146(1-3): 19-22.

24. Fuzzi S, Baltensperger U, Carslaw K, Decesari S, Denier van der Gon H, Facchini M C, Fowler D, Koren I, Langford B, Lohmann U, Nemitz E, Pandis S, Riipinen I, Rudich Y, Schaap M, Slowik JG, Spracklen DV, Vignati E, Wild M, Williams M and Gilardoni S. Particulate matter, air quality and climate: lessons learned and future needs. Atmos Chem Phys 2015; 15: 8217-8299.

25. Davis RE, McGregor GR and Enfield KB. Humidity: A review and primer on atmospheric moisture and human health. Environ Res 2016; 144: 106-116.

26. Jia L and Xu YF. Effects of relative humidity on ozone and secondary organic aerosol formation from the photooxidation of benzene and ethylbenzene. Aerosol Sci Technol 2014; 48: 1-12.

27. Li JY, Cleveland M, Ziemba LD, Griffin RJ, Barsanti KC, Pankow JF and Ying Q. Modeling regional secondary organic aerosol using the Master Chemical Mechanism. Atmos Environ 2015; 102: $52-61$.

28. Gao JJ, Tian HZ, Cheng K, Lu L, Zheng M, Wang SX, Hao JM, Wang K, Hua SB, Zhu CY and Wang Y. The variation of chemical characteristics of PM2.5 and PM10 and formation causes during two haze pollution events in urban Beijing, China. Atmos Environ 2015; 107: 1-8.

29. Silva HG, Conceição R, Wright MD, Matthews JC, Pereira SN and Shallcross DE. Aerosol hygroscopic growth and the dependence of atmospheric electric field measurements with relative humidity. J Aerosol Sci 2015; 85: 42-51.

30. Tian S, Pan Y, Liu Z, Wen T and Wang Y. Sizeresolved aerosol chemical analysis of extreme haze pollution events during early 2013 in urban Bei- jing, China. J Hazard Mater 2014; 279: 452-460.

31. Zanobetti A and Peters A. Disentangling interactions between atmospheric pollution and weather. J Epidemiol Commun H 2015; 69: 613-615.

32. Vu TV, Delgado-Saborit JM and Harrison RM. Review: Particle number size distributions from seven major sources and implications for source apportionment studies. Atmos Environ 2015; 122: 114-132.

33. Hirsikko A, Yli-Juuti T, Nieminen T, Vartiainen E, Laakso L, Hussein T and Kulmala M. Indoor and outdoor air ions and aerosol particles in the urban atmosphere of Helsinki: characteristics, sources and formation. Boreal Environ Res 2007; 12, 295-310.

34. Nazaroff W.W. Indoor particle dynamics. Indoor Air 2004; 14(7): 175-83.

35. Chithra VS and Shiva Nagendra SM. Particulate Matter Mass and Number Concentrations Inside a Naturally Ventilated School Building Located Adjacent to an Urban Roadway. J Inst Eng India Ser A 2014; 95(3): 143-149.

36. Markowicz P and Larsson L. Influence of relative humidity on VOC concentrations in indoor air. Environ Sci Pollut Res 2015; 22: 5772-5779.

37. Guo Z. A framework for modeling non-steady-state concentrations of semivolatile organic compounds indoors - II. Interactions with particulate matter. Indoor Built Environ 2014; 22(4): 685-700.

38. Hussein T, Korhonen H, Herrmann E, Hämeri K, Lehtinen KEJ and Kulmala M. Emission rates due to indoor activities: indoor aerosol model development, evaluation, and applications. Aerosol Sci Tech 2005; 39: 1111-1127.

39. Fang GC, Chang CN, Chu CC, Wu YS, Fu PPC, Chang SC and Yang IL. Fine (PM2.5), coarse (PM2.5-10), and metallic elements of suspended particulates for incense burning at Tzu Yun Yen temple in central Taiwan. Chemosphere 2003; 51(9): 983-991.

40. Wang B, Lee SC, Ho KF and Kang YM. Characteristics of emissions of air pollutants from burning of incense in temples, Hong Kong. Sci Total Environ 2007; 377(1): 52-60.

41. Zhang J, Chen W, Li J, Yu S and Zhao W. VOCs and Particulate Pollution due to Incense Burning in Temples, China. Procedia Eng 2015; 121: 992-1000.

42. Jeong CH, Evans GJ, Hopke PK, Chalupa D and Utell MJ. Influence of atmospheric dispersion and new particle formation events on ambient particle number concentration in Rochester, United States, and Toronto, Canada. J Air Waste Manage Assoc 2006; 56: 431-443. 